\title{
EFL Students' Perceptions at Sudanese University Level of Native and Non-Native English-Speaking Teachers
}

\author{
Mohammed A.M. Elomarabi \\ Department of English Language \& Linguistics -Faculty of Education-University of Kassala-Sudan \\ elomarabi11@gmail.com
}

\begin{abstract}
This paper attempts to investigate the issue of native and non-native English-speaking teachers (NESTs/NNESTs within the Sudanese university context). Employing two research tools (pulling together quantitative and qualitative methods), the study examined a group of participants (347) University English Language EFL students from seven sound Sudanese universities. The key data was collected from two resources; a questionnaire and a series of interviews. Afterwards, the data collected was, further, subjected to a statistical analysis. Having done so, a concise literature review of the study which presents the differences between native and non-native English-speaking teachers and to gain -in-depth- the Sudanese university EFL students' perceptions of the role of native and non-native English-speaking teachers inside the English language classrooms. The results are enlightening, as Sudanese university EFL students comprised in the sample find an overall positive satisfaction of both groups with relevant differences between the pedagogical behaviour of (NESTs/NNESTs), with the students' beliefs that NESTs/NNESTs can be equally qualified teachers with strengths and weaknesses for each.
\end{abstract}

Keywords: native and non-native; student perceptions; qualitative and quantitative data, multilingualism, speakerism

\section{Introduction}

It goes without saying that the topic of non-native English speakers as teachers of English has been a hot-button issue that dates back to the moment English language began to be taught worldwide. Surely, the native English-speaking teachers (NESTs) vs. non-native English-speaking teachers (NNESTs) dichotomy has created an ongoing debate which attached great importance of learning languages in general, and English language in particular. Not surprisingly, the native and non-native English-speaking teachers' issue has riveted attention and deserved discussion. In a way or another it has consolidated multiculturalism, multilingualism, and diversity which are all signs of strength in our country/ Sudan. There have been strenuous efforts and attempts to define both terms, and to draw a clear-cut distinction between them. Arguments in favour or against each one have been stated (Paikeday, 1985; Coppieters, 1987; Medgyes, 1992; Widdowson, 1992 \& Liu, 1999). Other scholars have put substantial exertion to shed more light on non-native English-speaking teachers and to give them a room in the career, regarding that their strengths are still comparatively unacquainted and their potential and contribution to the ELT field were underrated. Thus, for example, research has been carried out to destroy the so-called native speaker fallacy and caucuses such as the NNEST Caucus in TESOL have been created (Braine, 1999 \& Maum, 2002).

Paikeday, (1985) wrote a book under the eye-catching title of The Native Speaker is Dead! And (Davies 1991) claims: "The native speaker is a fine myth: we need it as a model, a goal, almost an inspiration. But it is useless as a measure" p.157. Though, the native and non-native division is still 
enormously utilized, with multifarious studies showing the differences between them and sketching out the pros and cons, the puissance and fragility of each option. Other scholars have focused on reinforcing the strengths of native and non-native teachers through united partaking of linguistic, cultural, and educational perceptions within a seamless collaborative joint (Matsuda, 1999). In same vein, what Matsuda (1999, p. 2) terms a "deficit model of teacher development", which views the native and non-native dichotomy as discrete (NESTs or NNESTs), competitive (NESTs vs. NNESTs), or subtractive (strengths minus weaknesses), would be substituted by a "collaborative model of teacher qualification", which would involve integrative (Ns and NNs), cooperative (mutual sharing), and additive (NESTs strengths plus NNESTs strengths) elements.

\section{Statement of the Problem}

Despite the fact that non-native English-speaking teachers (NNESTs) in (EFL) contexts outnumbered those whom the language is their mother tongue - where English language is a lingua franca or an international language.- yet, not many studies on NESTs and NNESTs conducted or examined students' attitudes towards these two groups of teachers. All this paves the way for Sudan to be an exemplary case study for detecting the real or potential issues/challenges of the topic. Furthermore, the English language teaching profession in many parts of the world - and in Sudan in particular- endorses a presupposition that native English-speaking teachers (NESTs) are the only perfect yardstick of spoken and written language, whereas non-native English-speaking teachers (NNESTs) are under qualified educators and deficient models. But does this idea agree with the views of EFL learners? To fill this gap, this paper reports on research carried out with university EFL students in Sudan probing their perceptions of learning English from NESTs and NNESTs.

\section{Objectives of the Study}

The main objective of this study is to completely and carefully examine the general perceptions of university EFL students of NESTs and NNESTs in Sudan. It also aims at finding out with which Sudanese university EFL students believe they learn more: with native or with non-native EFL teachers.

\section{The significance of the Study}

This study stems its importance from three aspects. First, it may render as one of few experimental studies to investigate Sudanese university EFL students' perceptions of their learning preferences for both NESTs and NNESTs in Sudan. Second, it could also enrich the literature of EFL teachers to get a better understanding of the students' awareness of the different English language teachers with regard to NESTs and NNESTs. Finally, both NESTs and NNESTs who want to gear up their development in the field can gain some glimpses from the results and take them into account in teaching the English language.

\section{Questions \& Hypotheses of the Study}

[1] How far do Sudanese university EFL students' perceptions concerning the English language instruction of native English-Speaking Teachers (NESTs) and non-Native English-Speaking Teachers (NNESTs) go?

[2] Which group of teachers do Sudanese university students prefer to learn English, Native EnglishSpeaking Teachers (NESTs) or Non-Native English Speaking Teachers (NNESTs) and why?

[3] What positive and negative experience do Sudanese university EFL students detect when learning from NNESTs and NESTs?

Built on the research questions, the following hypotheses can be drawn: 
[1] There is no significant difference in the respondents' perceptions of their NESTs or NNEST.

[2] There is no significant difference in the respondents' perceptions of the teaching strategies used by either NESTs or NNESTs.

[3] In general, Sudanese university EFL students will not show positive perceptions of either NESTs or NNESTs over the other."

\section{Literature Review}

\section{Native and non-Native Speakerism}

According to Holliday (2005), native-speakerism can be defined "as an established belief that 'native-speaker' teachers represent a 'Western culture' from which spring the ideals both of the English language and of English language teaching methodology" p.6. In other words, the central tenet of native-speakerism is developed from the claim that 'native speakers' of English have a special status to the language itself, in the sense that the ownership of it only belongs to them. In his view, division of native and non-native is existed, but it also entails some sort of downsides, deeprooted flaw or inability.

Braine (1999) suggests that native speakers themselves "do not speak the idealized, standardized version of their language" any more than non-native speakers, that both groups are affected in their speech "by geography, occupation, age, and social status" p.4. Jenkins (2000, pp.8-9) proposes an argument against the concept of a non-native speaker. She remarked that the term nonnative speaker misses to identify that many varieties of English in Outer Circle countries, such as Singapore, are spoken not only as official language but also in the home (...) that English is often one of the several languages available in the repertoires of the multilingual populations of, for example, Asian and African countries (...) [where] it is often difficult to ascertain which language is a person's L1 and which is their L2.

Moreover, Jenkins (2000) and Holliday (2005), and along with many others, call for the need to change some of the basic beliefs of Western philosophy and that native-non-native classification causes negative attitudes towards 'non-native' teachers and a lack of confidence in and out of 'nonnative' theory builders. And therefore, results in 'non-natives' being rejected places on EFL teacher training courses, slimed their chances to issue articles in sound/ notable international journals. Furthermore, the characterizing of so-called 'non-native speaker' is captious and a bit degrading. Conversely, others argue that it does depend on where one comes from and that the native-non-native speaker distinction exists, for better or worse, as part of the professional discourse and has, therefore, to be worked with.

Finally, to get over the difficulties of the native-non-native speaker issue, Jenkins (2000, p.10) offers another distinction between 'bilingual' and 'monolingual' English speakers, and a third term, 'non-bilingual English speakers' for people who 'are bilingual but not in English' and likes the sense that the norm is shifted from 'monolingual' to 'bilingual'. She, however, acknowledges that this distinction also has too many grey areas.

\section{Multi-Competence and Native-Speakerism}

The expression 'multi-competence' was primarily known as 'the compound state of a mind with two grammars' (Cook, 1991); in the context of his paper, 'grammar' was used in the Chomskyan sense of the total knowledge of language in the mind (the I-language) leading some people to infer wrongly that multi-competence was restricted to syntax. So multi-competence is now usually said to be 'the knowledge of more than one language in the same mind' (Cook, 1994, p.79). Multicompetence thus offers an opinion of second language acquisition (SLA) based on the second language (L2) user as a whole person rather than on the monolingual native speaker.

Multi-competence therefore encompasses the entire mind of the speaker, not merely their native language (L1) or their second. It postulates that someone who knows two or more languages is a 
different person from a monolingual and so requires to be looked at in their own right rather than as a deficient monolingual.

\section{Changing Patterns in the Use of English Language}

As noted by Jenkins (2000, p.7) the teaching of English to speakers of other languages has a history stretching back to the late $15^{\text {th }}$ century. From that time onwards, English has been taught, albeit intermittently, to people for whom it was not their mother tongue, whether to further trading and commercial interests, promote the empire, facilitate the everyday survival of refugees and immigrants, or for a combination of these causes. She proposes that until fairly recently, purpose of such teaching was directly: learners desire mostly to have a good command of spoken English to keep in touch with native speakers of English, who considered by all as accurate model of language, representatives of its norms. This was the situation regardless of the status of English as a 'foreign' or 'second' language. In order to accomplish their objectives, it is importantly vital for these English 'non-native speakers' to be as nearer as possible to native commonplace, essentially with regard to pronunciation.

Needless to say that, the English language is the most preferable and wished for second / foreign language in the whole globe - it is the language of many nations and cultures. As an outcome of the emergence of the new technologies - which have completely revolutionized the way we think, the way we work, communicate, share our thoughts and feelings- English language appeared on the top of languages which in turn affected all aspects of the society i.e. education, and communication, etc).

\section{Insights of Students toward (NESTs) and (NNESTs)}

Lately, studies investigating the positives and negatives of NESTs and NNESTs from a different angle i.e. students' perceptions have been carried out by a considerable number researchers. This is vital because students, by nature, are the consumers of their teachers' product and they are the real treasure in our back yard.

Kristy (2002) investigated $20 \mathrm{ESL/EFL} \mathrm{students} \mathrm{attitudes} \mathrm{toward} \mathrm{NNESTs} \mathrm{'} \mathrm{pronunciation} \mathrm{and}$ the attributes of speech that share in the student's' production, emulated with NESTs. The outcomes uncovered that, although students highly evaluated spoken language in EFL/ESL instructors as something crucial, it did not influence their attitudes toward NNESTs. Indeed, students held widely affirmative attitudes toward the teachers in their home countries and consider that spoken language was not as pertinent as it seemed in the first impressions.

In Mahboob's (2003) study on students' perceptions of NNESTs in the US. Results disclosed that both NESTs and NNESTs received positive and negative remarks. NESTs were remarkable for their oral/aural skills, vocabulary bank, and cultural knowledge, but were criticized for their poor knowledge of grammatical aspects of the language, their lack of experience as EFL/ESL learners they did not pass through the experience of being English language foreign/second learner- their difficulties in answering questions and their teaching methodology. However, NNESTs were valued for their experience as EFL/ESL learners, and the respondents also recognized their knowledge of grammar, hard work, ability to answer questions, and literacy skills. Surprisingly, as with Moussu (2010), negative response about NNESTs included poorer oral skills and lack of knowledge about "English-speaking culture".

In contrast, Medgyes (1994) argued that NNESTs might not be as skilful in the English language as NESTs, but skillfulness does not guarantee success in teaching because teaching may or may not be achieved at a high level of proficiency. He also added that ' a deficient command of English language may even have hidden advantages'. In a study that investigated 32 ESL/EFL students' perceptions toward their NESTs and NNESTs, Mahboob (2004) utilized a novel and insightful "discourse analytic" technique. The participants were asked to write a descriptive essay about their opinions in regard to their NESTs and NNESTs. The results showed that ESL students had no preference for NESTs and NNESTs since the two types of teachers were perceived to have 
strengths and weaknesses in English teaching. Some participants believed NESTs as better teachers of vocabulary and culture, while others supported NNESTs for the using of good teaching methods, the ability to answer students' questions, and being responsible for their English instruction.

In regard to Lasagabaster and Sierra's (2005, p.136) study in Spain, there were 76 EFL undergraduate students who completed a Likert scale questionnaire about their preferences toward NESTs' and NNESTs' English instruction. The results showed that students preferred to learn with NESTs in general, but the differences in preferences for NESTs and NNESTs were based on specific language skill areas. For example, learners preferred NESTs in "the production skills of speaking, pronunciation, and writing", while a positive sign towards NNESTs when it came to the teaching of grammatical aspects of language.

An attempt to distinguish between NNESTs and NESTs in China in terms of attitude, means of instruction and teaching results as perceived by 65 Chinese students. They were asked to comment on their NESTs and Chinese teachers of English. The results revealed no significant difference in students' perceptions of the two groups. The students are aware that both groups as hardworking and competent. Unlike NESTs, NNESTs' approaches to text materials are more varied and detailed (Liu \& Zhang, 2007).

Xiaoru (2008) investigated 75 Chinese male and female college students' perceptions of nonnative English speaker teachers. A questionnaire was used to collect data by means of both closed and open questions. A high proficiency in English ability, to use English functionally and the awareness of the culture of English speaking countries were the strengths observed in NESTs. In the case of NNESTs, the ability to empathize with students as fellow foreign language learners, a shared cultural background, and the emphasis they placed on grammar and strategies were seen as their strengths. The findings also indicate that the students have a clear preference for NESTs believing that they are more fluent and accurate with a special emphasis on their good pronunciation and sound knowledge of the target language (see also Park, 2009). The study concluded that Chinese students see their NESTs and NNESTs having their respective strengths.

Similar results could be found in Park's (2009) study. No overall preferences for NESTs over NNESTs were concluded by 177 Korean university students while investigating their preferences for English language teachers. It was remarkable that the participants in this study considered that an integration and cooperation of NESTs and NNESTs was appropriate and workable to enhance the possibility of learner's academic success.

In tendam, Alseweed's (2012) study found that university students prefer NESTs for specific language macro-skills (abstract aspects of the language). NNESTs are preferable for teaching writing, sub-writing skills and grammar. However, drawing a comparison from students view point between NESTs and NNESTs was not part of the study.

Another a study was conducted by Al-Nawrasy (2013) in UAE investigating the influencee of NNESTs in comparison with NESTs on students' achievement in speaking skill. The results revealed that there were no significant differences among students' overall speaking achievement test scores amongst the participants due to the nativeness of the teachers. However, the in-depth analysis showed that there was a significant correlation between nativeness and pronunciation in favour of the NESTs and a significant correlation between nativeness and in favour of the NNESTs. To sum up, a very important factor to emerge from the above studies is that issue of NESTS and NNESTS not yet come to conclusion.

\section{An Effective English Language Teacher}

Medgyes (1994, p.25) advanced three hypotheses based on his assumption that NESTs and NNESTs are 'two different species' "they both differ in terms of language proficiency, teaching practice (behaviour), and that both NESTs and NNESTs could be equally good teachers in their own terms". 
Medgyes (1994) conducted a survey of NESTs and NNESTs to ascertain their success in teaching English. He came out that the two categories had an equal chance of success as English language teachers. Results explained that the only area in which the NNESTs seemed to be less competent is English language proficiency which is in line with Samimy and Brutt-Griffler (1999) and Xiaoru (2008). Compared to their native-English-speaking colleagues who can be good language models for their students, NNESTs can be good learner models, having gone through the experience of learning English as a second or a foreign language as they have adopted language-learning strategies during their own learning process, most likely making them better qualified to teach those strategies (Medgyes, 1994).

According to Arikan (2010), who proposes that "teacher effectiveness is one of the most profound factors affecting the quality of the language learning process." p.210. A question, thus, comes to mind: What is a good English language teacher? In the same vein, Astor (2000, p.18), argues that a well-equipped teacher of English should be minimally competent in three fields of knowledge pedagogy: "methods in ELT, psycholinguistics and applied linguistics". Borg (2006) further provided five different traits to recognize the characteristics of good English language teachers: "personal qualifications, pedagogical skills, classroom practices, subject matter and psychological constructs such as knowledge and attitudes" p.8.

\section{Materials \& Method}

By adopting quantitative and qualitative methods along with employing two research tools, the study investigated a group of participants included (347) University English Language EFL students from seven sound Sudanese universities. The key data was collected from two resources; a questionnaire and a series of interviews. The questionnaire consists of two parts (see Appendix A). part (1) seeks the personal information of the respondents. Part (2), had (4) items all revolve around the importance of native English speaking teachers and non - native English speaking teachers. This question is supplemented with an open-ended question asking students to explain their choice of answer. Moreover, because of the normal constrains of the restricted form of the questionnaire, a semi-structured type interview (8 questions) was provided (see Appendix B). The interview was primarily exploratory in nature, and was meant to provide an in-depth understanding about Sudanese university students' awareness of the NESTS and NNESTs as well to guard against any inadequacies and pitfalls of other types of data collected for the study.

The study was carried out in seven universities inside Sudan with Sudanese ELF students who had experienced being taught English language by both types of teachers NESTs (BrE \& AmE) and NNESTs for two years. The respondents sample consisted of (347) male/ female university ELF students for the academic year (20016-2017). The number of years of studying English ranged from 7 to 11 years.

\section{Procedures}

Quantitative and qualitative data were collected in two phases via a questionnaire and semistructured interviews with Sudanese university EFL students. The overall awareness element was designed on the basis of 4 statements and open-ended question covering reasons underlying students' perceptions of their NESTs and NNESTs. The second stage consisted of interviews with 20 students who had experience with NESTs and NNESTs. Those students were randomly chosen to represent subjects of the study. The interviews were administered in English and Arabic languages so that students can express themselves precisely and clearly. Each candidate was asked to give his answers regarding the reasons underlying their preference for native and non-native EFL teachers, the appropriate level learners can benefit from either group of teachers or both, and with whom learners would learn better. Students were also encouraged to give comments or other additional information the interview questions did not cover. 


\section{Data Analysis}

Table 1. Students Institutional Affiliation

\begin{tabular}{|l|c|c|c|c|}
\hline \multicolumn{1}{|c|}{ School / Institute } & \multicolumn{2}{c|}{$\begin{array}{c}\text { Students } \\
\text { female male }\end{array}$} & account & $\%$ \\
& & & \\
\hline University of Kassala & 73 & 45 & 118 & 34 \\
\hline Nile Valley University & 32 & 47 & 79 & 22.8 \\
\hline University of Science \& Technology & 30 & 22 & 52 & 14.9 \\
\hline University of Khartoum & 7 & 7 & 14 & 4.03 \\
\hline Omdurman Islamic University & 12 & 18 & 30 & 8.64 \\
\hline University of Shendi & 4 & 18 & 22 & 6.34 \\
\hline Red Sea University & 13 & 19 & 32 & 9.2 \\
\hline \multicolumn{1}{|c|}{ Total } & 171 & 176 & 347 & 100 \\
\hline
\end{tabular}

Data gathered from the questionnaire are tabulated in Table (2) below:

Table 2. Sudanese University EFL students' perceptions of their NESTs and NNESTs

\begin{tabular}{|l|c|c|}
\hline & account & $\%$ \\
\hline 1. Constantly prefer to study with a native English teacher. & 54 & 15.6 \\
\hline 2. Constantly prefer to study with a non-native English- speaking teacher. & 43 & 12.4 \\
\hline 3. It doesn't matter if it is a native or non-native English-speaking teacher. & 117 & 33.71 \\
\hline $\begin{array}{l}\text { 4. Studying with a native or non -native teacher (it depends on his/her competence and the quality } \\
\text { of teaching). }\end{array}$ & 133 & 38.32 \\
\hline \multicolumn{1}{|c|}{ Total } & 347 & 100 \\
\hline
\end{tabular}

Table (2) above provides an answer for the first question of the study "How far do Sudanese university EFL students' perceptions concerning the English language instruction of native EnglishSpeaking Teachers (NESTs) and non-Native English-Speaking Teachers (NNESTs go)?" and also does confirm the first hypothesis "There is no significant difference in the respondents' perceptions of their NESTs or NNEST." As disclosed in the table (2) most of the respondents did not see any type of teachers as the best way to learn the English language. While $(38.32 \%)$ said that it would be better to have both native English-speaking teachers (NESTs) and non-native (NNESTs), (33.71\%) of the students said that it did not make a difference if the teacher was native or non-native. In contrast, $(15.6 \%)$ of the students desired to be within native English-speaking teachers (NESTs) classes, while only (12.4\%) answered that they would always want to be involved with non-native English-speaking teachers (NNESTs) classes.

The students' comments in the open-ended question related this with a highly percentage - to be taught- by both NESTs and NNESTs to several reasons, most important of which is that what really matters for the Sudanese university EFL students is that the teacher should know how to teach skillfully and effectively (34.6\%), should know the English language very well (22.8\%), should be highly competent and should be able to encourage/stimulate students to learn better (40.7\%). What is more, respondents identified three different situations in different learning levels in which specific type of teacher would be more suitable. (Table:3)

Table: 3 Students' choice of both groups of teachers for each learning level

\begin{tabular}{|l|l|l|l|}
\hline \multicolumn{1}{|c|}{ Teachers } & Level & N & \% \\
\hline NESTs & beginning & 72 & 44.4 \\
\hline NNESTs & intermediate and advanced/university education & 77 & 47.5 \\
\hline NNESTs or NNESTs & beginning level & 13 & 8.02 \\
\hline
\end{tabular}


As table (3) expresses, the choice of NNESTs for beginning levels can be associated with the reasons referred by students who preferred NNESTs, namely the use of Sudanese/Arabic when teaching English and the teachers' knowledge of their students' difficulties. These findings collaborate with studies such as Madrid (2004); Liu and Zhang (2007) and Park (2009) as students prefer both. Since the students in the present study had previous learning experiences with both types of teachers, they are able to decide with which type they would learn better. Some students justified their responses stating that they would need NNESTs at lower levels of education as they need a teacher who shares the same language and cultural background, but when they go higher up to the university level a NEST would be more helpful. This is consistent with Torres (2004), Madrid (2004), and Lasagabaster and Sierra (2002) who found that adult ESL/EFL students' general preference for NESTs increases as they move to more advanced levels of study.

The finding of the study supplies a reply to the second research question " Which group of teachers do Sudanese university EFL students prefer to learn English with, native English-speaking teachers (NESTs) or non-native English- speaking teachers (NNESTs) and why?" and it does prove and support the third research hypothesis "In general, Sudanese university EFL students will not show positive perceptions of either NESTs or NNESTs over the other." Coupled with that, these subjects also pointed out the most preferred reasons for students who had no preference for either type of teachers which in agreement with many experts' opinions.

- NESTs have larger and deeper natural understanding of the language pieces and give a greater amount of exposure in the class to learn vocabulary, expressions and phrasal verbs. (Arva \& Medgyes, 2000).

- NESTs are the model of correct accent and correct pronunciation and help to learn about the native culture. (Medgyes, 2005\& Al-Nawrasy, 2013)

- NNESTs have the same cultural background, can teach/explain in Sudanese/Arabic and they passed through the same experience, can understand/ know students difficulties and ways of thinking. (Braine, 2010).

Essentially, students clearly emphasized the importance of the teachers' pedagogic and linguistic competence regardless of the teachers' language affiliation. From among the students who preferred to be part of a native English teacher's class, (56) students provided a number of reasons. (Table 4).

Table: 4. Students' Reasons for Preferring NESTs

\begin{tabular}{|c|c|c|c|}
\hline \multirow[t]{8}{*}{ NESTs } & Reason & $\mathbf{N}$ & $\%$ \\
\hline & provide a better opportunity to pick up native accent/accurate pronunciation. & 15 & 26.8 \\
\hline & know the language better than non-native teachers. & 10 & 17.9 \\
\hline & are genuine parts of the native culture. & 10 & 17.9 \\
\hline & provide a better opportunity to speak/use English in class. & 4 & 7.1 \\
\hline & provide a better opportunity to listen to real English in class. & 4 & 7.1 \\
\hline & provide a better opportunity to learn vocabulary, expressions and phrasal verbs. & 9 & 16.0 \\
\hline & use direct method and help to learn the language with no L1 (Arabic) interference. & 4 & 7.1 \\
\hline
\end{tabular}

The most frequently stated reasons indicate that students expect to acquire native accent and learn about native culture. What is more, students mention that NESTs are more competent in the language, making it possible for them to learn and use English more effectively. These results support (Medgyes, 2005) that NESTs act as a perfect example in imitation and they are more competent in the language, making it possible for the students to learn and use the language more effectively with intensive knowledge about the target culture. As for the subjects who preferred NNESTs, (50) students indicated two reasons for doing so: (9) students said that NNESTs can teach/explain in Sudanese/ Arabic, while (41) students referred to the fact that NNESTs understand/know students' difficulties. This finding collaborates with (Medgyes, 1994, p.51) that NNESTs "provide an ideal model" for learners because they have acquired a complete skill in the English language, have teaching-learning strategies, able to respond to changes in their learners' mood, able to prepare solutions for language difficulties, show ability to understand learners 
experience and make use of the L1. Moreover, NNESTs have a big reservoir of cultural knowledge. Additionally, different opinions were expressed in the interviews. First of all, some of the students $(\mathrm{n}=4)$ expressed positive opinions about having native teachers:

Student 9: "There's nothing like a native speaker knowing the tricks of the language'.

Student 4: 'I think to be taught by a native teacher is something preferable to me and all other students because it will bridge/ compensate the lack of communication with native speakers'.

This finding can be explained that the salient merit of NESTs is apparently to be reached in their powerful linguistic and communicative ability of the L1 (English), and they can thus use it more naturally and spontaneously in a considerable variety of situations. (Árva \& Medgyes, 2000, p.261). However, some students pointed out some negative aspects of having NESTs:

Student 7: 'Many native teachers get their certification in a few month courses where they learn some classroom management and activities, whereas, in many countries we have to study 4 or 5 years to become a teacher of English. In Sudan we have to study not only the language but also grammar, linguistics, phonetics, English literature, English history, psychology, English for specific purposes, second language acquisition, just to name a few subjects we have to pass to get a teacher certification'.

Student 8: 'Just the fact of being a native teacher doesn't make you a good teacher. In fact, some of my native teachers were really bad at teaching. In my opinion, the mix of being a native, knowing the student's language, and being sympathetic to them is the key to a good teaching'.

RSU02: 'It's also my experience that some students and the parents of children believe that a native speaker teacher will be more beneficial than non- native speaker. This belief although misplaced has not been manufactured by the TEFL industry but by the faulty perception that native speakers are in some way more eminent to their non-native colleagues. Once again a good teacher is a good teacher, regardless of their country of birth and native tongue'.

The above responses corresponded with (Árva and Medgyes: 2000, p. 261), who stated that among all the remarkable weaknesses of native English teachers spotted were their unfruitful knowledge of grammar/ local culture". Conversely, knowledge of English grammar was often a provenance of satisfaction for non-native English language teachers, since they had mastered it comprehensively and thoroughly and were overqualified of producing accurate/ correct English expressions for building and use of well-structured English language.

Simultaneously, some students $(n=4)$ mentioned that both types of teachers are important and necessary in different learning levels:

Student 1: 'I believe as students we need to team-up native and non-native teachers. There are certain aspects of any language which are much easier for a native speaker to explain (...) I think in the beginning levels (...) it is important that somebody who speaks the same language to be there'.

Student 4: 'I feel that students at the higher levels benefit far more from a native teacher who has a much more emotional feel for their language. Things like phrasal verbs in English, for example, are more difficult for non-native speakers who may well not know them as there is an endless amount. The same goes for idioms. But I agree that non-native speakers, who go to great lengths to learn the grammar and rules may well find it easier to explain some grammar for example, whereas native speaker may not understand or at least may not be able to clearly explain'.

Finally, one student observed that the teacher's first language is not a central issue:

Student 9: 'I believe it doesn't make a difference whether it's native or non-native as long as it's a good teacher (... ) and has a good knowledge of the language'.

Therefore, these results give an answer to the research question no. 2 "What positive and negative experiences do Sudanese university EFL students detect when learning from NNESTs and NESTs?", and they also confirm the third research hypothesis "There is no significant difference in the 
respondents' perceptions of the teaching strategies used by either NESTs or NNESTs". Although the in-depth analysis shows very slight differences such as that NNESTs are serious teachers, with ability of understanding their students, farsighted to read their minds, and predict learning difficulties. Whereas NESTs are more innovative, with casual and flexible approaches and use a variety of materials. Further, these results are not consistent with some studies such as Lasagabaster and Sierra (2002); Medgyes (1994); Park (2009); Torres (2004) and Xiaoru (2008) who found that students have more preference for NESTs and their teaching strategies.

\section{Results}

Based on the Sudanese university EFL students' perceptions which were collected from the questionnaire and interviews, it was revealed that:

- Overall positive satisfaction of both groups (NESTs and NNETs) has been perceived by the participants.

- Both NESTs and NNESTs are seen as possibly evenly dynamic teachers by ELF students at the university level in Sudan.

- The NNESTs outclassed the NESTs in teaching grammatical aspects of English language and native culture whereas NESTs are deemed ideal pronunciation, fluency, listening and speaking teachers.

- NESTs may get access to the most modern and updated methods in their use of materials in the classroom, unlike their counterparts.

\section{Conclusion}

The ultimate goal of this study was to better understand and give more visibility to the Sudanese university EFL students' perceptions of their native English-speaking teachers and their home country teachers. The findings exposed no significant difference in the respondents' overall perceptions of their NESTs and NNESTs. Sudanese university EFL showed positive awareness towards their NESTs and NNESTs which gives the latter more confidence and visibility in the profession. The respondents believe that NNESTs are contributing effectively to the field of English language teaching by virtue of their own experiences as English language learners and teachers. However, their perception of their NESTs is stronger than that of NNESTs. The results also showed participants' preferences for NESTs increases as they go higher up in their education based on their previous learning experiences. Subjects of the study also exhibited a high explicit preference for NESTs over NNESTs in regard to the teaching strategies adopted by both types of teachers. The students believe that NESTs use motivating teaching methods which assist in learning the language in a better and sound way. However, the respondents are aware of the strengths of their NNESTs who can provide a serious learning environment and are able to respond to learners' needs. Although students showed a marked preference for NESTs, they actually showed warmer feelings toward NNESTs. Students made it clear that they do not behave differently with both types of teachers and they focus on their strengths.

Eventually, this article posits the following recommendations to be considered and taken into account whenever such kind of demarcation is drawn between native- English speaking teachers and non-native English speaking teachers.

- The strengths and weaknesses of NESTs and NNESTS need to be viewed as different from each other rather than superior to the other.

- NNESTs may take a privilege of their own strengths and better their teaching skills through professional teaching training courses.

- Effective cooperative teaching methods and pedagogical workshops of NESTs and NNESTs would be beneficial in Sudan. 
- Students' perceptions and preferences could be a useful source for educational administrators when recruiting EFL teachers.

- A team-teaching approach in which a NEST and a NNEST exchange opinions should be experimented with. This could help in developing cross-cultural awareness of all teachers as well as increasing language confidence of NNESTs.

- The effect of local teachers' accents on students' oral English performance and perceptions might be an important issue that needs to be revisited.

- NESTs should review and refer to NNESTs in regards to teaching grammatical rules and concepts as well as effective local pedagogical strategies.

- The Sudanese authorities should invest in NESTs, including inviting the United States Peace Corps to send volunteers to work in Secondary Schools and Universities in Sudan.

- On the plus side, positive steps are already into action. Some of the most noted ELT practitioners, along with organizations such as the British Council Teaching English team have already stated their vigorous corroboration for the TESOL members.

\section{References}

[1] O. Al- Nawrasy, (2012). The Effect of Native and Non-native English Language Teachers on Secondary Students' Achievement in Speaking Skills. Jordan Journal of Educational Science. Vol.9,No 2, pp-243254.

[2] M. A. Alseweed, (2012). University students' perceptions of the influence of native and nonnative teachers. English Language Teaching, 5(12), 42-53.

[3] A. Arikan, (2010). Effective English language teacher from the perspectives of pre-service and in-service teachers in Turkey. Electronic Journal of Social Sciences, 9(31), 209-223.

[4] V. Arva and P. Medgyes, (2000). Native and non-native teachers in the classroom. System, 28(3), 355-372.

[5] A. Astor, (2000). A qualified non-native English speaking teacher is second to none in the field. TESOL Matters, 10(2), 18-19.

[6] S. Borg, (2006). The Distinctive Characteristics of Foreign Language Teachers. Language Teaching Research, 10 (1), 3-31.

[7] G. Braine, (1999). Non-native educators in English language teaching. Mahwah, NJ: Lawrence Erlbaum Associates.

[8] V. Cook, (1991). 'Going Beyond the Native Speaker in Language Teaching'. TESOL Quarterly, $33(2), 185-210$.

[9] R. Coppieters, (1978). "Competence Difference between Native and Near-native Speakers", in Language, 63:544-73.

[10] A. Davies, (1991). The Native Speaker in Applied Linguistics. Edinburgh: Edinburgh University Press.

[11] A. Holliday, (2005). The struggle to Teach English as an International Language.Oxford: Oxford University Press.

[12] J. Jenkins, (2000). The Phonology of English as an International Language. Oxford: OUP.

[13] B.B. Kachru, (1985). Standards, Codification and Sociolinguistic Realism: The English language in the Outer Circle, in Quirk, R. and Widdowson, H.G.(eds) 1985, pp.10-30.

[14] D. Lasagabaster and J.Sierra, (2005). University Students' Perceptions of Native andNon-native Speaker Teachers of English. Language Awareness, 11(2), 132-138.

[15] M. Liu and L. Zhang, (2007). Student Perceptions of Native \& Non-native English Teachers' Attitudes, Teaching Skills Assessment and Performance.

[16] Asian EFL Journal, 9(4), Conference Proceedings, 157-166.

[17] A. Mahboob, (2003). Status of non-native English speaking teachers in the United States. Unpublished PhD Dissertation. Indiana University, Bloomington: NY. 
[18] A. Mahboob, (2004). Native or non-native: What do students enrolled in an intensive English program think? In L. Kammhi-Stein (Ed.), Learning and teaching from experience: Perspective on non-native English speaking professionals (pp. 121- 147). Ann Arbor, MI: University of Michigan Press.

[19] D. Madrid, (2004). Teacher and Student Preference of Native and non-Native Foreign Language teachers. Porta Linguarum, 2, 125-138.

[20] P. Matsuda, (1999). English as a second language Students' reaction to non-native speaking teachers. Master's thesis, Brighm Young University, Frovo.

[21]R. Maum, (2002). Non-native- English-speaking teachers in the English teaching profession. ERIC Digest. Retrieved April 2, 2011, from http://www.eric.ed.gov/PDFS/ED470982.pdf.

[22] P. Medgyes, (1992). Native or non-native: who's worth more? ELT Journal, 46(4), 340- 349.

[23] P. Medgyes, (1994). The non-native teachers. London: MacMillan.

[24] L. Moussu, (2010). Influence of teacher-contact time and other variables on ESL students' attitudes towards native-and nonnative-English-speaking teachers. TESOL Quarterly, 44(4), 746768.

[25] T. Paikeday, (1985). The Native Speaker is Dead! Ontario: Paikeday Publishing, Inc.

[26] E. Park, (2009). The Korean university students' preferences toward native English teachers. Modern English Education, 10(3), 114-130.

[27] K. S amimy and J. Bruit-Griffer (1999). To be a Native or Non-native Speaker: perceptions of 'nonnative Students' in a graduate TESOL Program. In Braine (ed), 127-144.

[28] J. W The Torres, (2004). Speaking up! Adult ESL students' perceptions of native and nonnative English speaking teachers (Unpublished master's thesis). The University of North Texas, Denton, TX.

[29] H. Widdowson, (1992). 'ELT and EL Teachers: Matter Arising'. ELT Journal, 46(4), 333- 339.

[30] C. Xiaoru, (2008). A SURVEY : Chinese College Students' Perceptions of Non-Native English Teachers. CELEA Journal, 31(3), 75-82. 


\section{Appendices}

\section{Appendix A \\ Students' Questionnaire}

\section{Dear participant,}

This questionnaire is designed as a data gathering tool for a a research paper entitled "EFL Students' Perceptions at Sudanese University Level of Native and Non-Native English-Speaking Teachers". Your answers will be greatly helpful to attain reliable and valid results. Therefore, your cooperation is highly appreciated. Your participation is voluntary and your responses will be kept strictly confidential and will be used for the purpose of this study only.

Name of the Researcher: Mohammed Abdou Mohammed Elomarabi

Affiliation: Department of English Language \& Linguistics Kassala University/ Sudan

Address: Kassala -Sudan- elomarabi11@gmail.com- mob: 00249912474387

\section{Personal information}

Name: (optional)

College:

Gender:

\section{What is the best way to learn English language? Please, tick $(\checkmark)$ one ONLY.}

\begin{tabular}{l|l|} 
1. Constantly prefer to study with a native English teacher. & \\
\hline 2. Constantly prefer to study with a non-native English- speaking teacher. & \\
3. It doesn't matter if it is a native or nonnative English-speaking teacher. & \\
4. Studying with a native or non -native teacher (it depends on his/her & \\
competence and the quality of teaching). & \\
\hline Why? &
\end{tabular}

\section{Appendix B \\ Students' Semi-structured Interview Guide}

Introduction

This interview aims at investigating "EFL Students' Perceptions at Sudanese University Level of Native and Non-Native English-Speaking Teachers". Your answers will be greatly helpful to attain reliable and valid results. Therefore, your cooperation is highly appreciated. Your participation is voluntary and your responses will be kept strictly confidential and will be used for the purpose of this study only.

Name of the Researcher: Mohammed Abdou Mohammed Elomarabi 
Affiliation: Department of English Language \& Linguistics Kassala University/ Sudan

Address: Kassala -Sudan- elomarabi11@gmail.com- mob: 00249912474387

\section{Personal information}

Name: (optional)

College:

Gender:

The interview covers the following agenda:

[1] According to your own point of view what is meant by a native English language teacher and a non-native English language teacher?

[2] How do you see (perceived strengths \& weaknesses) NESTs when act as instructors of English language to ESL/EFL learners?

[3] Are there any professional, linguistic and personal qualifications where NESTs/NNESTs seem to be better/overqualified than their counterparts?

[4] Do you think that NNESTs sharing the students' same culture (religion, ethnicity, language, etc.) helps a teacher develop rapport with the students?

[5] If you have the choice of teachers, why would you prefer/choose a NEST/NNEST to take an English language course with?

[6] Who do you think is more capable/ informative/ resourceful and possess some cultural background knowledge about diversity of cultures a NEST or NNEST?

[7] Do you think that both types of teachers have a role to play in terms of careful monitoring, ensuring the students that they know what they are supposed to do and are carrying out the tasks correctly?

[8] Do you believe that there is a certain type of teacher (Native-speaker or Nonnative-speaker) as the best/exemplary model of learning English language?

Thank you very much for your cooperation and help! 